The Journal of Animal \& Plant Sciences, 31(3): 2021, Page: 650-656

ISSN (print): 1018-7081; ISSN (online): 2309-8694

\title{
ADDITION OF ALPHA-LIPOIC ACID IN SEMEN EXTENDER IMPROVES POST-THAW ANTIOXIDANT PROFILE AND SEMEN QUALITY OF ACHAI (BOS INDICUS) CATTLE BULLS
}

\author{
M. Ayaz ${ }^{1}$, A. Ahmed ${ }^{1}$, M. I. R. Khan ${ }^{1}$, M. S. Yousaf ${ }^{2}$, B. U. Din³ and A. Riaz, ${ }^{1}{ }^{*}$ \\ ${ }^{1}$ Department of Theriogenology, ${ }^{2}$ Department of Physiology, University of Veterinary and Animal Sciences, Lahore, \\ Pakistan $-54000 ;{ }^{3}$ Cattle Breeding and Dairy Farm, Harichand, Charsadda, KPK, Pakistan \\ *Corresponding Author's E-mail: dramjadriaz@uvas.edu.pk
}

\begin{abstract}
The effect of Alpha-lipoic acid (ALA) on lipid peroxidation, catalase activity and post-thaw semen quality of Achai bulls (Bos indicus) was studied. Semen samples $(\mathrm{n}=28)$, collected from adult Achai bulls $(\mathrm{n}=4)$ at weekly intervals, were diluted with Tris-citric acid egg yolk extender having various concentrations of ALA $(0.00,0.25,0.50,1.00$ and $2.00 \mathrm{mM})$ and frozen in liquid nitrogen $\left(-196^{\circ} \mathrm{C}\right)$. Post-thaw semen assessment revealed that the lipid peroxidation decreased, while catalase activity increased $(\mathrm{P}<0.05)$ in all extenders containing ALA as compared to control, except in extender containing $2.00 \mathrm{mM}$ in which catalase activity decreased $(\mathrm{P}>0.05)$ than control. Moreover, post-thaw semen quality parameters i.e., sperm viability and plasma membrane integrity were higher $(\mathrm{P}<0.05)$ in extender having 0.25 and $0.50 \mathrm{mM}$ ALA compared to control, whereas mitochondrial membrane potential was significantly improved only with $0.50 \mathrm{mM}$ ALA as compared to control and all other ALA concentrations used. However, acrosome and DNA integrity of spermatozoa increased in extender supplemented with $0.25,0.50$ and $1.00 \mathrm{mM}$ ALA $(\mathrm{P}<0.05)$ compared to control. Computer Assisted Semen Analysis (CASA) of post-thaw semen revealed that total motility (\%) and curvilinear velocity $(\mu \mathrm{m} / \mathrm{s})$, progressive motility $(\%)$, progressive fast motility $(\%)$ and beat cross frequency $(\mathrm{Hz})$, and straight-line velocity $(\mu \mathrm{m} / \mathrm{s})$ and average path velocity $(\mu \mathrm{m} / \mathrm{s})$ were higher $(\mathrm{P}<0.05)$ for 0.50 and $1.00 \mathrm{mM}, 0.25$ and $0.50 \mathrm{mM}$ and 0.50 and $2.00 \mathrm{mM}$ ALA concentrations, respectively, than control. In conclusion, the addition of $0.50 \mathrm{mM}$ ALA in Tris-citric acid, fructose, egg yolk glycerol extender can perform optimum among all ALA concentrations $(0.00,0.25,1.00$ and $2.00 \mathrm{mM})$ used, in terms of minimizing the oxidative stress and improving the post-thaw semen quality of Achai bulls.
\end{abstract}

Keywords: Bos indicus, Achai bulls, Alpha-lipoic acid, Post-thaw semen quality, Antioxidant enzyme, Computer Assisted Semen Analysis.

\section{INTRODUCTION}

Achai is a dwarf-sized, dairy as well as light draught cattle breed, well-known for its better tolerability for harsh environmental conditions (Saleem et al., 2013). The home tract of this breed is the Hindu Kush mountains of northern Pakistan extending to neighboring areas of Afghanistan. This breed can survive in the mountainous region under hilly and sub-hilly subsistence production system (Khan et al., 2008). Milk produced by $\sim 49.07 \%$ population of the Achai breed ranges between $\sim 1501$ to 2100 liters per lactation, while the remaining population (41.76\%) produces milk around $\sim 1001$ to 1500 liters per lactation (Uddin et al., 2014). Hence, there is a high scope of breed improvement in Achai cattle through artificial insemination (AI).

In Pakistan, conception rates through AI range from 38 to $62 \%$ (Anzar et al., 2003). The problems related to AI services include sub-optimal semen processing, lack of farmers' awareness and skilled AI technicians, improper heat detection, and availability of liquid nitrogen for storage of frozen semen under field conditions (Anzar et al., 2003). During sperm cryopreservation, reactive oxygen species (ROS) like hydrogen peroxide, superoxide anion and hydroxyl radical are produced and deteriorate the sperm membrane stability. The unstable sperm plasma membrane results in altered motility patterns, reduced mitochondrial potential and abridged acrosome/ DNA integrity (Waterhouse et al., 2010).

During the freeze-thaw process, about $50 \%$ of cells are damaged due to osmolality and oxidative stress (Watson, 2000). Oxidative stress to the spermatozoa is the major sequel of cryopreservation, results in irreversible damage to sperm organelles and changes in enzymatic profile, along with a reduction in sperm motility, plasma membrane integrity, and ultimately fertility (Bucak et al., 2009a; Bucak et al., 2009b). Polyunsaturated fatty acids are found in large quantities in sperm plasma membrane which makes it more vulnerable to oxidative stress (Alvarez and Storey, 1995). Nature has equipped the spermatozoa with an intracellular enzymatic defense mechanism to counter the ROS (Alvarez et al., 1987; Lewis et al.,1995).To cope 
with this problem, the intracellular antioxidant system could be strengthened through addition of extracellular non-enzymatic antioxidants (Nair et al., 2006). Several non-enzymatic antioxidants such as Taurine, Glutathione, Alpha-Lipoic acid (ALA), Trehalose, Methionine, Carnitine, and vitamin $\mathrm{E}$ and $\mathrm{C}$ have been used in bovine semen extenders to improve post-thaw sperm quality (Bucak et al., 2010; Iqbal et al., 2016).

Alpha-Lipoic acid is a short-chain fatty acid which is water and fat-soluble and is considered as a universal antioxidant due to its better permeability across the cell membrane (Ibrahim et al., 2008). As high levels of ROS produced during cryopreservation damage cellular respiration (Bilodeau et al., 2002), ALA helps in mitochondrial respiration (Lovell et al., 2003) by enhancing Krebs cycle production of ATPs through pyruvate dehydrogenase and alpha-ketoglutarate dehydrogenase co-enzymes activation (Long et al., 2009). Further, ALA protects against ROS by forming the metal layer around cell membrane (Packer et al., 1995). It also enhances other antioxidants like vitamin $\mathrm{C}$ in the presence of glutathione (Ibrahim et al., 2008). ALA has also been reported to increase sperm motility during invitro incubation of the bull spermatozoa (Ibrahim et al., 2011). More specifically, it has been observed that ALA improves rapid forward progression and straight linear velocity, and limits ROS production (Ma et al., 2011). Based on the observations, it was hypothesized that supplementation of ALA in semen diluent will improve the post-thaw sperm quality of Achai bulls. Therefore, the aims of the present study were: 1) to assess the oxidative stress through lipid peroxidation and catalase activity (as an indicator of antioxidant activity), and 2) to evaluate the post-thaw semen quality after addition of different concentrations of ALA in semen extender for Achai bulls.

\section{MATERIALS AND METHODS}

Animals and semen collection: Four adult Achai bulls, maintained at the Cattle Breeding and Dairy Semen Production Unit, Harichand, KPK (Latitude: $34^{\circ} 23^{\prime} 1.19^{\prime \prime} \mathrm{N}$ and Longitude: $\left.71^{\circ} 48^{\prime} 10.79^{\prime \prime} \mathrm{E}\right)$ were used in the current study. All bulls were provided seasonal fodder at the rate of $10 \%$ body weight concentrates 2 to $3 \mathrm{~kg}$ daily and water ad libitum. An artificial vagina $\left(42^{\circ} \mathrm{C}\right)$ was used to collect semen from bulls $(n=4)$ once in a week for eight weeks, with a total of 32 semen samples. The initial motility, volume and concentration of each ejaculate were assessed and the semen samples were pooled. After pooling, motility was again evaluated before further processing. One pooled sample having $<65 \%$ motility was not further processed.

Semen Processing, Extension, and Freezing: A total of $100 \mathrm{ml}$ Tris-citric acid, fructose, egg yolk glycerol extender ( $\mathrm{pH} 6.8$; Tris; w/v 2.42\%, citric acid $1.32 \% \mathrm{w} / \mathrm{v}$, fructose $1 \% \mathrm{w} / \mathrm{v}$; Merck, streptomycin sulphate $100 \mu \mathrm{g}$ per ml, benzylpenicillin 1000 IU per ml; Sigma, glycerol $7 \% \mathrm{v} / \mathrm{v}$ and egg yolk $20 \% \mathrm{v} / \mathrm{v}$ ) was prepared on each collection day and poured equally into five graduated tubes. Briefly, two molar stock solution of ALA was prepared by dissolving $2.06 \mathrm{~g}$ of ALA in $5 \mathrm{ml}$ distilled water and sodium hydroxide solution (Gohar et al., 2014). Different concentrations i.e., 0.00 (control), 0.25, $0.50,1.00$, and $2.00 \mathrm{mM}$ of ALA were prepared by adding $0.00,15,30,60$ and $120 \mu \mathrm{l}$ of stock solution into graduated tubes containing extender. Pooled semen samples were divided into five aliquots and added into graduated tubes kept at $37^{\circ} \mathrm{C}$, so that final sperm concentration was $40 \times 10^{6}$ live sperms per $\mathrm{ml}$ of extended semen in each tube. All samples were cooled to $4^{\circ} \mathrm{C}$ in a cold cabinet for 4 hours, filled in $0.5 \mathrm{ml}$ French straws at the rate of $20 \times 10^{6}$ live sperm per straw. All straws were initially exposed to liquid nitrogen (LN) vapors at $-80^{\circ} \mathrm{C}$ for eight minutes and frozen into $\mathrm{LN}(-$ $196^{\circ} \mathrm{C}$ ). All straws were kept in LN for a minimum of one week and shifted to Theriogenology laboratory of University of Veterinary and Animal Sciences, Lahore for post-thaw semen analysis.

\section{POST-THAW SEMEN EVALUATION}

Catalase activity: Each frozen straw was thawed $\left(37^{\circ} \mathrm{C}\right.$ for 30 seconds) and spermatozoa were lysed using an ultrasonic liquid processor (ULP-750; Biotechnology Medical Services, USA), as described previously (Akalin et al., 2016). After centrifugation (3000 rpm for 5 minutes), $50 \mu \mathrm{l}$ supernatant was dispensed into a cuvette containing $500 \mu \mathrm{l}$ of $\mathrm{H}_{2} \mathrm{O}_{2}$ (test sample), and $500 \mu \mathrm{l} \mathrm{H}_{2} \mathrm{O}$ contained in another cuvette as a control test. Besides, cuvettes filled with $550 \mu \mathrm{l} \mathrm{H}_{2} \mathrm{O}$, and $500 \mu \mathrm{l} \mathrm{H}_{2} \mathrm{O}_{2}$ and 50 $\mu 1 \mathrm{H}_{2} \mathrm{O}$ were kept as blank and standard, respectively. All the cuvettes (blank, standards, test, and control) were incubated at $37^{\circ} \mathrm{C}$ for $3 \mathrm{~min}$ and added with $2 \mathrm{ml}$ of ammonium molybdate. Finally, $10 \mu \mathrm{l}$ from each cuvette was examined for absorbance at $374 \mathrm{~nm}$, using a spectrophotometer (UV-2800; BMS; USA). Catalase activity in the sample was determined by using the following equation (Hadwan and Abed, 2016).

$$
\begin{gathered}
\text { Semen catalase activity: } \\
(K U)=\frac{2303}{t} *\left\{\log 5^{\circ} / S-M\right\} * V T / V S
\end{gathered}
$$

Where $\mathrm{t}=$ total time, $\mathrm{S}^{\mathrm{o}}=$ absorbance of standard tubes, $\mathrm{S}=$ absorbance of the test tube, $\mathrm{M}=$ absorbance of control test, $\mathrm{VT}=$ total volumes of reagents in test tubes, and $\mathrm{VS}=$ volume of semen

Lipid peroxidation: Malondialdehyde (MDA) concentration in frozen-thawed semen was measured with thiobarbituric acid assay (TBA), as described previously (Sohail et al., 2018). Briefly, semen from each concentration of alpha-lipoic acid was thawed $\left(37^{\circ} \mathrm{C}\right)$ and 
mixed with $200 \mu \mathrm{l}$ of $8 \%$ sodium dodecyl sulfate solution and $750 \mu \mathrm{l}$ of $20 \%$ acetic acid in separate graduated tubes. Later, $1.5 \mathrm{ml}$ of thiobarbituric acid and distilled water were added to make a total volume of $4 \mathrm{ml}$. The solution was then heated to $95^{\circ} \mathrm{C}$ for one minute and left to cool at room temperature for 30 minutes. Afterward, 5 $\mathrm{ml}$ butanol was added and the mixture was centrifuged at $4000 \mathrm{rpm}$ for 15 minutes. Finally, a spectrophotometer (UV-2800; BMS; USA) was used to assess $100 \mu 1$ of the supernatant layer for absorbance at $492 \mathrm{~nm}$ wavelength. The standard curve against known concentrations of Tetramethoxy Propane (TMP) i.e., 0.00, 0.78, 1.5, 3.1, $6.2,12.5,25,50$ and $100 \mu \mathrm{M} / \mathrm{L}$ was utilized for calculation of MDA concentration $(\mu \mathrm{M} / \mathrm{L})$.

Sperm motility parameters, velocity distribution, and kinematics: A total of $10 \mu \mathrm{l}$ of frozen-thawed semen from each concentration of ALA was evaluated for overall sperm motility, progressive motility and motility kinematics using a preheated glass slide and coverslip under $100 \mathrm{x}$ magnification (AndroVision CASA system; Minitube, Germany). At least 400 spermatozoa per sample were counted in multiple microscopic fields. Sperm motility kinematics such as straight-line velocity (VSL $\mu \mathrm{m} / \mathrm{s}$ ), curvilinear velocity (VCL $\mu \mathrm{m} / \mathrm{s}$ ), average path velocity (VAP $\mu \mathrm{m} / \mathrm{s}$ ), linear distance (DSL $\mu \mathrm{m}$ ), distance average path (DAP $\mu \mathrm{m}$ ), amplitude of lateral head displacement (ALH $\mu \mathrm{m})$, beat cross frequency (BCF $\mathrm{Hz}$ ), linearity (VAP/VCL) and straightness (VSL/VCL) were analyzed. The computer-assisted semen analysis was performed with standard settings as followed: standard frame rate: 59; Spermatozoa were considered immotile when amplitude of lateral head displacement $(\mathrm{ALH})<1.0000$ and curvilinear velocity $(\mathrm{VCL})<$ $24.0000 \mu \mathrm{m} / \mathrm{s}$. Spermatozoa were considered local motile when straight-line velocity $(\mathrm{VSL})<24.0000 \mu \mathrm{m} / \mathrm{s}$ and VCL $<48.0000 \mu \mathrm{m} / \mathrm{s}$. Spermatozoa were considered circular motile when path radius $>10.0000$. Progressive motile spermatozoa had path radius $>10.0000$ and VCL $<120.0000 \mu \mathrm{m} / \mathrm{s}$.

Plasma membrane integrity (PMI\%): Hypo-osmotic swelling test (HOST) was performed for the evaluation of PMI of spermatozoa. A $500 \mu$ of HOS solution (190 mOsmol kg-1) was mixed with $50 \mu \mathrm{l}$ of semen from each concentration of ALA and incubated at $37^{\circ} \mathrm{C}$ for 30 minutes in a water bath. A total of one hundred spermatozoa were observed under phase-contrast microscope (400x; Olympus, Japan). Spermatozoa having an intact plasma membrane appeared swollen or coiled tailed (Khan and Ijaz, 2008).

Sperm Viability (\%): Viability of spermatozoa was judged using Propidium Iodide (PI) under a fluorescent microscope (480/550 nm excitation/barrier filter; CX41 Olympus, Japan). A $50 \mu 1$ Tris citric acid-fructose (TCF) was mixed with $50 \mu \mathrm{l}$ of semen from each concentration of ALA and centrifuged (3000 rpm for 5 minutes) to obtain a sperm pellet. A $2.5 \mu \mathrm{l}$ of PI was added to the sperm pellet after resuspending it in TCF to a final volume of $47.5 \mu \mathrm{l}$ and then incubated at $37{ }^{\circ} \mathrm{C}$ for $5 \mathrm{~min}$. At least 200 spermatozoa were counted under multiple microscopic fields for viability. Non-viable sperm appeared red under the fluorescence light, however viable spermatozoa did not retain PI (Aquila et al., 2011).

Acrosome integrity (\%): Acrosome integrity was assessed by using normal apical ridge (NAR) solution consisting of $1 \%$ formal citrate (formaldehyde 37\%; v/v and $2.9 \%, \mathrm{w} / \mathrm{v}$ trisodium citrate dehydrate; Merck). $50 \mu \mathrm{l}$ of $1 \%$ formal citrate and $500 \mu \mathrm{l}$ post-thawed semen were mixed and incubated for 30 minutes. At least 200 spermatozoa were observed under a phase-contrast microscope (400x; BX 51, Olympus, Japan). Spermatozoa with intact acrosome had a sharp black crescent on apical ridges (Rasul et al., 2001).

Mitochondrial membrane potential: An equal volume $(50 \mu \mathrm{l})$ of post-thawed semen and Tris citric acid-fructose (TCF) was mixed and centrifuged at $3000 \mathrm{rpm}$ for 5 minutes. The sperm pellet was supplemented with TCF to make a total volume of $245 \mu \mathrm{l}$ including $5 \mu \mathrm{l}$ Rhodamine (RH-123, Sigma Aldrich, USA), and incubated $\left(25^{\circ} \mathrm{C}\right)$ for 20 minutes. A $5 \mu$ drop of semen was observed using a fluorescence microscope (480/550 nm excitation/barrier filter; CX41 Olympus, Japan). At least 200 spermatozoa were examined. Spermatozoa with normal intact mitochondrial membrane appeared green under fluorescence at the midpiece region (Dodaran et al., 2015).

DNA integrity (\%): DNA integrity was assessed using Acridine Orange (AO). Briefly, post-thawed semen (100 $\mu \mathrm{l})$ and TCF $(200 \mu \mathrm{l})$ were mixed, and centrifuged (3000 rpm for 15 minutes) to obtain a sperm pellet which was resuspended in TCF to make a smear on a glass slide. Air-dried semen smears were kept for 2 hours in Carnoy's solution followed by a Tampon solution for 5 minutes at $60^{\circ} \mathrm{C}$. Finally, Semen smears were kept in an acridine orange solution for 5 minutes. A total of 200 spermatozoa were observed for the presence of green (intact DNA) or red (damaged DNA) color under a fluorescence microscope (CX41; Olympus, Japan; Tejada et al., 1984).

Statistical Analysis: Values are expressed as mean \pm standard error of the mean. One way analysis of variances (ANOVA) was applied to analyze the effect of ALA on each semen quality parameter and differences between concentrations were analyzed by Duncan's multiple range test through SPSS (version 16.0) software. 


\section{RESULTS}

The post-thaw profile of catalase $(\mathrm{Ku} / \mathrm{L})$ was higher $(\mathrm{P}<0.05)$ at $0.50 \mathrm{mM}$ of ALA concentration as compared to control and all other concentrations. The difference among 1.00, 2.00mM ALA concentrations and control was non-significant $(\mathrm{P}>0.05)$ in terms of catalase profile with minimum value for $2.00 \mathrm{mM}$ concentration. On the other hand, lipid peroxidation $(\mu \mathrm{M} / \mathrm{L})$ in all concentrations of ALA was lower $(\mathrm{P}<$ $0.05)$ than control with non-significant $(\mathrm{P}>0.05)$ difference among all ALA concentrations (Table 1).

Post-thaw sperm viability percentage was improved $(\mathrm{P}<0.05)$ by 0.25 and $0.50 \mathrm{mM}$ ALA concentrations as compared to control and other ALA concentrations, where $2.00 \mathrm{mM}$ significantly $(\mathrm{P}<0.05)$ decreased sperm viability as compared to control and all ALA concentrations. Similar trend was observed for plasma membrane integrity percentage with exception of non-significant difference $(\mathrm{P}>0.05)$ among 0.25 and $2.00 \mathrm{mM}$ ALA concentrations, and $2.00 \mathrm{mM}$ ALA with control. The difference among $0.25,1.00,2.00 \mathrm{mM}$ ALA concentrations and control in terms of mitochondrial membrane potential was found non-significant $(\mathrm{P}>0.05)$ with maximum value observed for $0.50 \mathrm{mM}$ ALA concentration $(\mathrm{P}<0.05)$. Moreover, acrosome integrity percentage was higher $(\mathrm{P}<0.05)$ at $0.25,0.50$ and $1.00 \mathrm{mM}$ ALA concentrations as compared to control, exhibiting non-significant difference $(\mathrm{P}>0.05)$ among $0.25,1.00$ and $2.00 \mathrm{mM}$ ALA concentrations. In addition, DNA integrity percentage was significantly higher $(\mathrm{P}<$ $0.05)$ at $0.25 \mathrm{mM}, \quad 0.50 \mathrm{mM}$ and $1.00 \mathrm{mM}$ ALA concentrations as compared to $2.00 \mathrm{mM}$ and control (Table 2).

Post-thaw total sperm motility, progressive motility and progressive fast motility percentages were improved $(\mathrm{P}<0.05)$ with $0.50 \mathrm{mM}$ ALA as compared to $0.25 \mathrm{mM}, 1.00 \mathrm{mM}, 2.00 \mathrm{mM}$ concentrations and control, showing non-significant difference $(\mathrm{P}>0.05)$ among $0.25, \quad 1.00$ and $2.00 \mathrm{mM}$ ALA concentrations. Additionally, the values for curvilinear velocity $(\mu \mathrm{m} / \mathrm{s})$ and average path velocity $(\mu \mathrm{m} / \mathrm{s})$ were higher $(\mathrm{P}<0.05)$ at $0.50 \mathrm{mM}$ ALA as compared to control and other ALA concentrations. Moreover, the straight line velocity $(\mu \mathrm{m} / \mathrm{s})$ was higher for 0.50 and $2.00 \mathrm{mM}$ ALA concentrations as compared to control, with nonsignificant differences $(\mathrm{P}>0.05)$ among $0.25,1.00 \mathrm{mM}$ and control, and among all ALA concentrations. Beat cross frequency $(\mathrm{Hz})$ was higher $(\mathrm{P}<0.05)$ for 0.25 and $0.50 \mathrm{mM}$ ALA concentrations as compared to control, exhibiting non-significant difference $(\mathrm{P}>0.05)$ among 1.00, 2.00mM ALA concentrations and control (Table 3).

Table 1. Effect of alpha-lipoic acid in semen extender on post-thaw semen enzymatic profile of Bos indicus (Achai) bulls.

\begin{tabular}{cccccc}
\hline \multirow{2}{*}{ Post thaw enzymatic profile } & \multicolumn{5}{c}{ Concentration of Alpha-lipoic acid (mM) } \\
\cline { 2 - 5 } & $\mathbf{0 . 0 0}$ & $\mathbf{0 . 2 5}$ & $\mathbf{0 . 5 0}$ & $\mathbf{1 . 0 0}$ & $\mathbf{2 . 0 0}$ \\
\hline Catalase activity $(\mathrm{Ku} / \mathrm{L})$ & $23.61 \pm 4.00^{\mathrm{c}}$ & $34.82 \pm 4.95^{\mathrm{b}}$ & $49.21 \pm 2.77^{\mathrm{a}}$ & $24.80 \pm 3.77^{\mathrm{bc}}$ & $22.23 \pm 1.54^{\mathrm{c}}$ \\
Lipid peroxidation $(\mu \mathrm{M} / \mathrm{L})$ & $10.33 \pm 0.06^{\mathrm{a}}$ & $9.03 \pm 0.17^{\mathrm{b}}$ & $8.60 \pm 0.27^{\mathrm{b}}$ & $8.80 \pm 0.40^{\mathrm{b}}$ & $8.91 \pm 0.16^{\mathrm{b}}$ \\
\hline
\end{tabular}

Different superscripts in a row indicate significant differences $(\mathrm{p}<0.05)$ among groups.

Table-2.Effect of alpha-lipoic acid in semen extender on post-thaw semen parameters (motility, viability, plasma membrane, mitochondrial membrane potential, Acrosome, and DNA integrity percentage) of Bos indicus (Achai) bulls' spermatozoa. $(n=4$ bulls and $n=28$ ejaculates)

\begin{tabular}{|c|c|c|c|c|c|}
\hline \multirow{2}{*}{ Semen quality parameters } & \multicolumn{5}{|c|}{ Concentration of Alpha-lipoic acid (mM) } \\
\hline & 0.00 & 0.25 & 0.50 & 1.00 & 2.00 \\
\hline Sperm Viability (\%) & $44.21 \pm 1.14^{\mathrm{c}}$ & $47.57 \pm 0.86^{b}$ & $51.07 \pm 0.87^{\mathrm{a}}$ & $44.92 \pm 0.46^{\mathrm{c}}$ & $41.64 \pm 0.38^{d}$ \\
\hline PMI (\%) & $43.28 \pm 0.44^{\mathrm{c}}$ & $45.07 \pm 0.61^{\mathrm{b}}$ & $53.14 \pm 0.41^{\mathrm{a}}$ & $43.35 \pm 0.58^{\mathrm{c}}$ & $43.92 \pm 0.49^{\mathrm{bc}}$ \\
\hline Mitochondrial Membrane potential (\%) & $44.92 \pm 0.29^{\mathrm{b}}$ & $46.42 \pm 0.94^{b}$ & $50.71 \pm 0.44^{\mathrm{a}}$ & $44.71 \pm 0.76^{\mathrm{b}}$ & $45.57 \pm 0.61^{b}$ \\
\hline Acrosome Integrity $(\%)$ & $48.42 \pm 0.44^{\mathrm{c}}$ & $50.14 \pm 0.57^{\mathrm{ab}}$ & $50.71 \pm 0.21^{\mathrm{a}}$ & $50.07 \pm 0.55^{\mathrm{ab}}$ & $48.71 \pm 0.58^{\mathrm{bc}}$ \\
\hline DNA integrity (\%) & $96.07 \pm 0.74^{\mathrm{b}}$ & $98.14 \pm 0.43^{\mathrm{a}}$ & $98.92 \pm 0.20^{\mathrm{a}}$ & $98.00 \pm 0.83^{\mathrm{a}}$ & $95.64 \pm 0.76^{b}$ \\
\hline
\end{tabular}

Values with different superscripts in row indicate significant $(\mathrm{P}<0.05)$ difference among groups. 
Table 3. Effect of alpha-lipoic acid in semen extender on post thaw CASA parameters (motilities, velocity distribution and kinematics) of Bos indicus (Achai) bulls' spermatozoa. $(n=4$ bulls and $n=28$ ejaculates)

\begin{tabular}{|c|c|c|c|c|c|}
\hline \multirow{2}{*}{ Semen quality parameters } & \multicolumn{5}{|c|}{ Concentration of Alpha-lipoic acid (mM) } \\
\hline & 0.00 & 0.25 & 0.50 & 1.00 & 2.00 \\
\hline Total motility $(\%)$ & $41.53 \pm 0.68^{c}$ & $45.80 \pm 0.80^{\mathrm{bc}}$ & $56.76 \pm 2.59^{\mathrm{a}}$ & $46.98 \pm 1.75^{\mathrm{b}}$ & $42.36 \pm 1.09^{\mathrm{bc}}$ \\
\hline Progressive motility (\%) & $33.47 \pm 1.78^{\mathrm{c}}$ & $39.32 \pm 1.08^{\mathrm{b}}$ & $49.40 \pm 2.12^{\mathrm{a}}$ & $38.29 \pm 1.44^{\mathrm{bc}}$ & $34.79 \pm 1.36^{\mathrm{bc}}$ \\
\hline Progressive fast motility (\%) & $13.67 \pm 1.60^{\mathrm{c}}$ & $20.40 \pm 1.71^{\mathrm{b}}$ & $27.79 \pm 1.75^{\mathrm{a}}$ & $16.66 \pm 1.22^{\mathrm{bc}}$ & $17.34 \pm 1.62^{\mathrm{bc}}$ \\
\hline Progressive slow motility (\%) & $19.59 \pm 0.76$ & $18.33 \pm 1.84$ & $21.54 \pm 1.80$ & $20.72 \pm 1.24$ & $16.50 \pm 1.63$ \\
\hline Curvilinear velocity $(\mu \mathrm{m} / \mathrm{s})$ & $54.47 \pm 2.97^{\mathrm{c}}$ & $63.62 \pm 2.01^{\mathrm{bc}}$ & $82.26 \pm 3.27^{\mathrm{a}}$ & $64.82 \pm 2.83^{\mathrm{b}}$ & $63.98 \pm 4.25^{\mathrm{bc}}$ \\
\hline Straight line velocity $(\mu \mathrm{m} / \mathrm{s})$ & $22.01 \pm 1.51^{\mathrm{b}}$ & $26.03 \pm 1.66^{\mathrm{ab}}$ & $30.42 \pm 0.84^{\mathrm{a}}$ & $25.94 \pm 1.98^{\mathrm{ab}}$ & $27.10 \pm 1.61^{\mathrm{a}}$ \\
\hline Average path velocity $(\mu \mathrm{m} / \mathrm{s})$ & $27.58 \pm 1.47^{\mathrm{c}}$ & $32.12 \pm 1.51^{\mathrm{bc}}$ & $40.03 \pm 1.02^{\mathrm{a}}$ & $32.19 \pm 2.00^{\mathrm{bc}}$ & $33.05 \pm 1.87^{\mathrm{b}}$ \\
\hline Linear distance $(\mu \mathrm{m})$ & $7.42 \pm 0.76$ & $9.49 \pm 0.82$ & $8.03 \pm 0.85$ & $8.06 \pm 0.38$ & $7.37 \pm 0.53$ \\
\hline Distance average path $(\mu \mathrm{m})$ & $9.92 \pm 0.75$ & $12.20 \pm 0.81$ & $11.79 \pm 0.77$ & $10.39 \pm 0.55$ & $9.93 \pm 0.52$ \\
\hline $\begin{array}{l}\text { Amplitude of lateral head } \\
\text { displacement }(\mu \mathrm{m})\end{array}$ & $0.97 \pm 0.02^{\mathrm{a}}$ & $0.77 \pm 03^{\mathrm{b}}$ & $0.72 \pm 0.03^{\mathrm{b}}$ & $0.78 \pm 0.02^{\mathrm{b}}$ & $0.72 \pm 0.02^{\mathrm{b}}$ \\
\hline Beat cross frequency $(\mathrm{Hz})$ & $6.61 \pm 0.35^{\mathrm{c}}$ & $8.17 \pm 0.47^{\mathrm{ab}}$ & $8.79 \pm 0.76^{\mathrm{a}}$ & $7.49 \pm 0.29^{\mathrm{abc}}$ & $6.94 \pm 0.29^{\mathrm{bc}}$ \\
\hline Linearity (VSL/VCL) & $0.40 \pm 0.01$ & $0.40 \pm 0.01$ & $0.37 \pm 0.01$ & $0.40 \pm 0.02$ & $0.42 \pm 0.01$ \\
\hline Straightness (VSL/VAP) & $0.79 \pm 0.01$ & $0.80 \pm 0.01$ & $0.76 \pm 0.01$ & $0.80 \pm 0.01$ & $0.81 \pm 0.00$ \\
\hline
\end{tabular}

Values with different superscripts in the row indicate significant $(\mathrm{P}<0.05)$ differences among groups

\section{DISCUSSION}

The current study was designed to explore the effect of ALA on cryopreservation of Achai bull spermatozoa (Bos indicus). ALA is considered as universal antioxidant based on its scavenger effect for free radicals (Packer et al., 2001). Further, catalase is considered as a major antioxidant enzyme that promotes the defense system of spermatozoa against oxidative stress. In post-thaw semen enzymatic evaluation, catalase activity improved significantly $(\mathrm{P}<0.05)$. The optimal concentration of ALA was $0.50 \mathrm{mM}$. The property of ALA to improve catalase activity seems to be due to enhanced glucose uptake by cells that results in further increment in nicotinamide adenine dinucleotide and nicotinamide adenine dinucleotide phosphate levels as reported previously in different organs of old aged rats (Arivazhagan et al., 2000).

The level of oxidative stress can be evaluated by MDA, an end product of lipid peroxidation (LPO). The lipid peroxidation profile in all ALA treated groups was lower than control $(\mathrm{P} \leq 0.05)$. These findings are in accordance with the past study on rat sperm, in which alpha-lipoic acid supplementation of extender reduced oxidative stress and improved semen quality (Selvakumar et al., 2006).

During post-thaw semen evaluation, sperm motility is considered as an important parameter. It is believed that the sperm cells with rapid forward movement have greater capability to reach the site of fertilization. ALA acts as an antioxidant, as well as coenzymes of ATPs based on various enzyme systems like alpha-ketoglutarate dehydrogenase and pyruvate dehydrogenase. This results in increased energy availability to spermatozoa by enhanced mitochondrial membrane potential and ultimately leads to increased sperm motility (Bilska and Wlodek, 2005). The results of this study revealed that pre-freeze treatment of semen extender with $0.50 \mathrm{mM}$ and $0.25 \mathrm{mM}$ ALA significantly increased post-thaw semen quality in terms of sperm motility, viability, and plasma membrane integrity $(\mathrm{P} \leq$ $0.05)$. These results are in accordance with previous reports which indicate improved semen quality following the addition of ALA in extender for cattle (Ibrahim et al., 2011), buffalo (Gohar et al., 2014), and buck semen (Ibrahim et al., 2008). The ability of ALA to improve semen quality has also been demonstrated by feed supplementation in rats (Selvakumar et al., 2006; Othman et al., 2012; Yeni et al., 2012). However, the results of current study are not in line with an earlier study on equine semen (Hussain et al., 2011), where ALA showed no beneficial impact on post thaw semen quality parameters.

For active motile sperms, healthier mitochondria with high membrane potential are obligatory (Suarez et al., 2007; Ahmed et al., 2016). It has been reported that ALA promotes mitochondrial respiration (Lovell et al., 2003), and results in additional ATPs production (Long et $a l ., 2009)$ that results in improved DNA integrity. These observations are in agreement with our data, which shows that the addition of ALA in semen extender results in improved mitochondrial membrane potential and DNA integrity.

In the current study, post-thawed computerassisted semen analysis of semen diluted with extender containing $0.50 \mathrm{mM}$ ALA concentration showed significant improvement $(\mathrm{P} \leq 0.05)$ in quality parameters like total motility, progressive motility, velocity distribution, and kinematics. A previous study conducted on bovine (Bucak et al., 2015) semen reported 
significantly enhanced post-thawed sperm motility in an extender containing $1.0 \mathrm{mM}$ ALA in combination with $2.0 \mathrm{mM}$ cysteamine. Moreover, increasing the concentration of ALA decreased sperm motility which was attributed to the change in $\mathrm{pH}$ of the sperm environment towards high acidic, which is detrimental to sperm and results in immobility (Olmsted et al., 2000). In our study, the best post-thaw semen quality was obtained in semen extender containing $0.50 \mathrm{mM}$ ALA, which is a lower concentration in comparison with $1.0 \mathrm{mM}$ used in an earlier study (Bucak et al., 2015).

\section{REFERENCES}

Ahmed, H., S. M. H. Andrabi and S. Jahan (2016). Semen quality parameters as fertility predictors of water buffalo bull spermatozoa during lowbreeding season. Theriogenology. 86(6): 15161522.

Akalin, P. P., N. Baspinar, K. Coyan, M.N. Bucak, S. Güngör and C. Öztürk (2016). Effects of ultrasonication on damaged spermatozoa and mitochondrial activity rate. Turk. J. Vet. Anim. Sci. 40(2): 195-199.

Alvarez, J. G. and B. T. Storey (1995). Differential incorporation of fatty acids into and peroxidative loss of fatty acids from phospholipids of human spermatozoa. Mol. Reprod. Dev. 42(3): 334-346.

Alvarez, J.G., J.C. Touchstone, L. Blasco and B.T. Storey (1987). Spontaneous lipid peroxidation and production of hydrogen peroxide and superoxide in human spermatozoa Superoxide dismutase as major enzyme protectant against oxygen toxicity. J. Androl. 8(5): 338-348.

Anzar, M., U. Farooq, M.A. Mirza, M. Shahab and N. Ahmad (2003). Factors affecting the efficiency of artificial insemination in cattle and buffalo in Punjab, Pakistan. Pakistan Vet. J. 23(3): 106113.

Aquila, S., F. Giardano, C. Guido, V. Rago and A. Carpino (2011). Nitric oxide involvement in the acrosome reaction triggered by leptin in pig sperm. Reprod. Biol. Endocrin. 9: 133.

Arivazhagan, P., T. Thilakavathy and C. Panneerselvam (2000). Antioxidant lipoate and tissue antioxidants in aged rats. J. Nutr. Biochem. 11(3): 122-7.

Bilodeau, J.F., S. Blanchette, N. Cormier and M.A. Sirard (2002). Reactive oxygen species-mediated loss of bovine sperm motility in egg yolk Tris extender: protection by pyruvate, metal chelators and bovine liver or oviductal fluid catalase. Theriogenology. 57(3): 1105-1122.

Bilska, A. and L. Wlodek (2005). Lipoic acid-the drug of the future. Pharmacol. Rep. 57(5): 570-577.
Bucak, M.N., S. Gungor, C. Özturk, K. Çoyan, M.B. Ataman and N. Baspinar (2015). Combination of cysteamine and lipoic acid can improve postthawed bovine sperm quality. Cryobiology. 3(71): 547.

Bucak, M.N., S. Sarı̈zkan, P.B. Tuncer, P.A. Ulutaş and H.I. Akçadağ (2009a). Effect of antioxidants on microscopic semen parameters, lipid peroxidation and antioxidant activities in Angora goat semen following cryopreservation. Small Ruminant Res. 81(2): 90-95.

Bucak, M.N., T.B. Tuncer, S. Sarıözkan and P.A. Ulutaş (2009b). Comparison of the effects of glutamine and an amino acid solution on post-thawed ram sperm parameters, lipid peroxidation and antioxidant activities. Small Ruminant Res. 81(1): 13-17.

Bucak, M.N., P.B. Tuncer, S. Sarı̈zkan, N. Başpınar, M. Taşpınar, K. Çoyan and S. Ilgaz (2010). Effects of antioxidants on post-thawed bovine sperm and oxidative stress parameters: antioxidants protect DNA integrity against cryodamage. Cryobiology. 61(3): 248-253.

Dodaran, H.V., M. Zhandi, M. Sharafi, E. Nejati-Amiri, A. Nejati-Javaremi, A. MohammadiSangcheshmeh, M.A.M.M. Shehab-El-Deen and M. Shakeri (2015). Effect of ethanol induced mild stress on post-thawed bull sperm quality. Cryobiology. 71(1): 12-17.

Gohar, A., H. Khan, M. Yousaf, J. Ahmad, Q. Ali, M. Khan, D. Khan, Y. Hayat, F. Ali and I. Ahmad (2014). Assessment of alpha-lipoic acid inclusion in semen extender on cryopreservation of Nili-Ravi buffalo bull spermatozoa. Life Sci. J. 11(9s): 45-50.

Hadwan, M.H. and H.N. Abed (2016). Data supporting the spectrophotometric method for the estimation of catalase activity. Data in brief. 6: 194-199.

Hussain, J., A. Salam and A. Gohar (2011). A study on the cryopreservation of stallion semen with Alpha-lipoic acid. J. Pharma. Res. Int. 1(1): 2126.

Ibrahim, S.F., F.H.F. Jaffar, K. Osman and S.F. Syed (2011). Bull spermatozoa motility: optimization of coenzyme $\mathrm{q} 10$ and alpha-lipoic acid concentration. IIOAB J. 2(5): 8-13.

Ibrahim, S.F., K. Osman, S. Das, A.M. Othman, N.A. Majid and M.P.A. Rahman (2008). A study of the antioxidant effect of alpha-lipoic acids on sperm quality. Clinics. 63(4): 545-550.

Iqbal, S., S.M.H. Andrabi, A. Riaz, A.Z. Durrani and N. Ahmad (2016). Trehalose improves semen antioxidant enzymes activity, post-thaw quality, and fertility in Nilli Ravi buffaloes. Theriogenology. 85: 954-959. 
Khan, M.S., Z. Rehman, M.A. Khan and S. Ahmad (2008). Genetic resources and diversity in Pakistani cattle. Pakistan Vet. J. 28(2): 95-102.

Khan, M.I.R., and A. Ijaz (2008). Effects of osmotic pressure on motility, plasma membrane integrity and viability in fresh and frozen-thawed buffalo spermatozoa. Animal 2(4): 548-553.

Lewis, S.E., P.M. Boyle, K.A. McKinney, I.S. Young and W. Thompson (1995). Total antioxidant capacity of seminal plasma is different in fertile and infertile men. Fertil. Steril. 64(4): 868-870.

Long, J., F. Gao, L. Tong, C.W. Cotman, B.N. Ames and J. Liu (2009). Mitochondrial decay in the brains of old rats: ameliorating effect of alpha-lipoic acid and acetyl-L-carnitine. Neurochem. Res. 34(4): 755-763.

Lovell, M.A., C. Xie, S. Xiong and W.R. Markesbery (2003). Protection against amyloid beta peptide and iron/hydrogen peroxide toxicity by alphalipoic acid. J. Alzheimer's Dis. 5(3): 229-239.

Ma, H., F. Quan, D. Chen, Y. Zheng, B. Zhang, Y. Wang and Y. Zhang (2011). Protective function of alpha-lipoic acid on sperm motility and mitochondrial function during goat spermmediated gene transfer. Small Ruminant Res. 99(2): 191-198.

Nair, S.J., A. Brar, C. Ahuja, S. Sangha and K. Chaudhary (2006). A comparative study on lipid peroxidation, activities of antioxidant enzymes and viability of cattle and buffalo bull spermatozoa during storage at refrigeration temperature. Anim. Reprod. Sci. 96(1-2): 21-29.

Olmsted, S., N.H. Dubin, R.A. Cone and T.R. Moench (2000). The rate at which human sperm are immobilized and killed by mild acidity. Fertil. Steril. 73(4): 687-693.

Othman, A.I., M.A. El-Missiry, K.M. Koriem and A.A. El-Sayed (2012). Alfa-Lipoic acid protects testosterone secretion pathway and sperm quality against 4-tert-octylphenol induced reproductive toxicity. Ecotoxicol. Environ. Saf. 81: 76-83.

Packer, L., K. Kraemer and G. Rimbach (2001). Molecular aspects of lipoic acid in the prevention of diabetes complications. J. Nutr. 17(10): 888-895.

Packer, L., E.H. Witt, and H.J. Tritschler (1995). Alphalipoic acid as a biological antioxidant. Free Radic. Biol. Med. 19(2): 227-250.
Rasul, Z., N. Ahmad and M. Anzar (2001). Changes in motion characterstics, plasma membrane integrity, and acrosome morphlogy during cryopreservation of buffalo spermatoza. J. Androl. 22(2): 278-283.

Saleem, M., I. Rahim, S. Jalali, H. Rueff, M. Khan, D. Maselli, U. Wiesmann and S. Muhammad (2013). Morphological characterization of Achai cattle in sedentary and transhumant systems in Pakistan. Anim. Genet. Resour. 52: 83-90.

Selvakumar, E., C. Prahalathan, P.T. Sudharsan and P. Varalakshmi (2006). Chemoprotective effect of lipoic acid against cyclophosphamide-induced changes in the rat sperm. J. Toxicol. 217(1): 7178.

Sohail, A., M.I.R. Khan, M. Ahmad and S. Iqbal (2018). Effect of age on lipid peroxidation of fresh and frozen-thawed semen of Nili-Ravi buffalo bulls. Ital. J. Anim. Sci. 17(3): 730-735.

Suarez, S.S., B. Marquez, T.P. Harris and J.C. Schimenti (2007). Different regulatory systems operate in the midpiece and principal piece of the mammalian sperm flagellum. Soc. Reprod. Fertil. Suppl. 65: 331-334.

Tejada, R.I., J.C. Mitchell, A. Norman, J.J. Marik and S. Friedman (1984). A test for the practical evaluation of male fertility by acridine orange (AO) fluorescence. Fertil. Steril. 42(1): 87-91.

Uddin, H., H.U. Khan, M.I. Khan, R. Khan and A. Naveed (2014). Productive and reproductive performance of Achai cattle maintained at livestock research \& development station Surezai Peshawar, Pakistan. J. Anim. Health Produc. 22(1):13-19

Waterhouse, K.E., A. Gjeldnes, A. Tverdal, P.M. De Angelis, W. Farstad, M. Haard and E. Kommisrud (2010). Alterations of sperm DNA integrity during cryopreservation procedure and in vitro incubation of bull semen. Anim. Reprod. Sci. 117: 34-42.

Watson, P. (2000). The causes of reduced fertility with cryopreserved semen. Anim. Reprod. Sci. 60: 481-492.

Yeni, D., A. Fidan, I. Ciğerci, M. Konuk, F. Avdatek and M. Gündoğan (2012). Effect of $\alpha$-lipoic acid on sperm quality, reproductive tract measures in thinner exposed rats. Andrologia. 44(s1): 74-80. 